\title{
PERBEDAAN DISFUNGSI SEXUAL WANITA YANG MELAHIRKAN SECARA PERVAGINAM DENGAN EPISIOTOMY MEDIOLATERAL DAN SEKSIO SESAREA Irwanto, Yahya ${ }^{1^{*}}$, Mustofa, Edy ${ }^{1}$
}

\author{
Departemen Obstetri dan Gynecology Rumah Sakit Saiful Anwar Malang, Fakultas Kedokteran Universitas \\ Brawijaya Malang \\ Email* : yahyairwanto50@ub.ac.id
}

\begin{abstract}
Generally, the causes of Postpartum Female Sexual Dysfunction (PPFSD) are dyspareunia, perineal pain, the discomfort of incision lesion including surgery, reduction of libido, lack of lubrication in the vagina, changes in seeing body image to be negative, and anorgasm irelated to pain and trauma. Perineal pain and dyspareunia are post partum problems which occur frequently and interfere with normal sexual function, that usually are caused by perineal trauma, episiotomy, and child birth instrumentation. This study was conducted by a cross-sectional study. Research subjects consisted of women post vaginal delivery with mediolateral episiotomy and postcesarean section. Each group consisted of 45 people. After three months post partum sexual function as sessed using FSFI scores (Female Sexual Function Index) as well as an assess ment of demographic data include age, religion, education, employment, insurance coverage/BPJS, gestational age, birthweight, stitches condition, medical treatment, nursing, assistance of baby sitter and problems in the family. The data had to fulfill the inclusion and exclusion criteria in the form of question naires were further tested withc hi-square analysis and independent t-test. In the demographic data analysis withc hi-squareanalys is didn't find any significant differences between the two groups, with $p>0.05$. The sexual dysfunction among women after vaginal delivery with mediolateral episiotomy and cesarean section there was no significant difference $p=0.081$, and $p>0.05$. On the FSFI scores domains there are significant differences between the two group son the variables of sexual desire, orgasm, pain and FSFI total scores.
\end{abstract}

Keywords: Sexual Dysfunction, mediolateral episiotomy, cesarean section, FSFI scores

\begin{abstract}
ABSTRAK
Penyebab Post partum Female Sexual Dysfunction (PPFSD) pada umumnya adalah dispareunia, nyeri perineal, ketidaknyamanan luka insisi termasuk di dalamnya tindakan pembedahan, berkurangnya libido, kurang lubrikasi pada vagina, perubahan citra tubuh menjadi negatif serta anorgasme yang dihubungkan dengan nyeri dan trauma.Nyeri perineum dan dispareunia adalah masalah pasca persalinan yang sering terjadi dan mengganggu fungsi seksual
\end{abstract}


yang normal, yang biasanya terjadi akibat dari trauma perineum, episiotomi, dan instrumentasi persalinan. Penelitian ini dilakukan dengan metode crosssectional study. Subjek penelitian terdiri dari perempuan paca persalinan pervaginam dengan episiotomi mediolateral dan pasca seksiosesarea. Masing-masing kelompok terdiri dari 45 orang. Setelah tiga bulan pasca persalinan dilakukan penilaian fungsi seksual menggunakan skor FSFI (FemalSexualFunction Index) serta dilakukan penilaian data demografis mencakup umur, agama, pendidikan, pekerjaan, tanggungan asuransi/ BPJS, usia kehamilan, berat badan bayi lahir, kondisi luka jahitan, perawatan medis kembali, menyusui, bantuan pengasuh bayi dan masalah dalam keluarga. Data memenuhi kriteria inklusi dan eksklusi berupa kuesioner selanjutnya diuji dengan analisis chi-square dan independent t-Test. Pada analisis data demografi dengan analisis chi-square tidak didapatkan perbedaan bermakna diantara kedua kelompok, dengan $p>0,05$. Pada disfungsi seksual antara perempuan pasca persalinan pervaginam dengan episiotomi mediolateral dan seksiosesarea tidak didapatkan perbedaan bermakna $p=0,081$ dimana $p>0,05$. Pada domain Skor FSFI terdapat perbedaan signifikan antara kedua kelompok pada variabel hasrat seksual, orgasme, nyeri dan skor total FSFI. Tidak didapatkan perbedaan disfungsi seksual yang bermakna pada tiga bulan pasca persalinan diantara kelompok perempuan pasca persalinan pervaginam dengan episiotomi mediolateral dengan seksiosesarea di Rumah Sakit dr. Saiful Anwar Malang.

Kata kunci: Disfungsi Seksual, episiotomumediolateral, seksiosesarea

*Korespondensi: Yahya Irwanto. Surel: yahyairwanto50@ub.ac.id 


\section{PENDAHULUAN}

Perempuan pasca melahirkan akan mengalami beberapa perubahan berkaitan dengan proses persalinan yang dialami.Perubahan tersebut dapat mempengaruhi kebutuhan seksualitas perempuan dan pasangan. Ketidaknyamanan fisik dan psikologis tersebut menjadi faktor yang mempengaruhi keharmonisan hubungan dalam suatu perkawinan (Breslin\& Lucas, 2003). Penyebab Postpartum Female Sexual Dysfunction (PPFSD) pada umumnya adalah dispareunia, nyeri perineal, ketidaknyamanan luka insisi termasuk di dalamnya tindakan pembedahan, berkurangnya libido, kurang lubrikasi pada vagina, perubahan citra tubuh menjadi negatif serta anorgasme yang dihubungkan dengan nyeri dan trauma.

Berdasarkan data epidemiologi dari Survei Kesehatan Nasional dan Kehidupan Sosial di Amerika (2005) menemukan dari 1749 perempuan, sebanyak sepertiga perempuan kurang berminat melakukan hubungan seksual dan hampir seperempat tidak mengalami orgasme. Sekitar $20 \%$ dari perempuan kesulitan dalam lubrikasi dan 20\% menemukan seks tidak menyenangkan.Pada 6 bulan pasca melahirkan, 16 orang (61\%) terjadi peningkatan hubungan seksual, sedangkan 10 perempuan (39\%) merasakan sama seperti keadaan sebelum hamil. Pada 6 bulan rata-rata hubungan seksual itu terus meningkat, tetapi masih jauh lebih rendah dibandingkan sebelum hamil.

Nyeri perineum dan dispareunia adalah masalah pasca persalinan yang sering terjadi dan mengganggu fungsi seksual yang normal, yang biasanya terjadi akibat dari trauma perineum, episiotomi, dan instrumentasi persalinan (Basson, 2004). Episiotomi dapat mengakibatkan gangguan fungsi dasar panggul, lesi pada saraf pudenda, hasil penjahitan yang asimetris, endometriosis, luka yang melebar dengan perdarahan, infeksi, serta penyembuhan yang lebih lama, yang semuanya dapat menyebabkan dispareunia ataupun gangguan fungsi seksual lainnya dikemudian hari (Abdool, etal., 2009).

Bila dibandingkan dengan persalinan spontan vagina, tampaknya logis untuk berasumsi bahwa wanita yang melahirkan melalui seksio saesarea akan lebih kecil kemungkinannya untuk mengalami nyeri perineum, sejak risiko persalinan dengan episiotomi ataupun dibantu ditiadakan (Buhling, etal., 2006). Namun demikian, seksiosesarea sendiri (terutama yang non elektif) bukannya tanpa bahaya, bahkan terhadap seksualitas itu sendiri. Komplikasi utama persalinan seksiosesarea adalah kerusakan organ-organ seperti vesikaurinaria dan uterus saat dilangsungkannya operasi, komplikasi anesthesi, perdarahan, infeksi, dan tromboemboli.

\section{METODE PENELITIAN Rancangan Penelitian}

Rancangan penelitian ini adalah studi potong lintang analitik (crosssectional study). Populasi target pada penelitian ini adalah wanita pasca persalinan pervaginam dengan episiotomi dan pasca seksio sesarea. Populasi terjangkau pada penelitian ini adalah wanita primipara pasca persalinan pervaginam dengan episiotomi dan pasca seksio sesarea yang melahirkan di Rumah Sakit dr. Saiful Anwar Malang dari bulan April 
2014 sampai dengan bulan Juni 2014 .

\section{Populasi Penelitian}

Penelitian ini adalah wanita primipara pasca persalinan pervaginam dengan episiotomi dan pasca seksio sesarea yang melahirkan di Rumah Sakit dr. Saiful Anwar Malang dari bulan April 2014 sampai dengan bulan Juni 2014.

$\begin{array}{cl}\text { Pada } & \text { penelitian ini } \\ \text { menggunakan } & \text { populasi yang }\end{array}$ memenuhi kriteria inklusi dan eksklusi. Kriteriainklusi pada penelitian ini :1. Sudah menikah. 2.Pasca melahirkan pertama kali. 3.Umur antara tujuh belas sampai dengan tiga puluh lima tahun. 4.Riwayat persalinan pervaginam dengan episiotomi mediolateral. 5 . Riwayat persalinan dengan seksio sesarea. 6.Bayi hidup saat penelitian/wawancara (tiga bulan postpartum).7. Tinggal bersama suami yang mampu melakukan hubungan seksual paling sedikit satu bulan terakhir.8. Bersedia ikut serta dalam penelitian ini dengan menandatangani informedconsent.9. Tidak ada komplikasi akibat persalinan atau pada luka episiotomi dan seksio sesarea.10. Tidak terdapat riwayat disfungsi seksual sebelum persalinan. Sedangkan Kriteria eksklusi adalah :1. Sedang dalam perawatan penyakit medis. 2.Riwayat persalinan pervaginam dengan bantuan alat (vakum, forceps). 3. Riwayat persalinan dengan kehamilan multiple. 4. Riwayat Abortus. 5.Sedang menggunakan kontrasepsi hormonal : pil kombinasi. 6 . Tidak melakukan hubungan seksual pada satu bulan terakhir. 7. Tidak bersedia melanjutkan penelitian.

\section{Teknik Pengumpulan Data}

Sampel penelitian diambil secara consecutive sampling. Setelah dilakukan sampling kepada sampel yang memenuhi kriteria inklusi dan eksklusi, diberikan penjelasan tentang tujuan dan manfaat penelitian ini, selanjutnya bagi yang bersedia mengikuti penelitian ini dilakukan informed consent. Selanjutnya pasien melakukan pengisian kuisioner, dan peneliti melakukan anamnesis dan penelusuran rekaman medik untuk melengkapi data yang diperlukan. Jika pasien tidak mampu atau kesulitan untuk membaca maka peneliti akan membantu untuk membacakan kuisioner yang tersedia. Kemudian sampel dikelompokkan menjadi kelompok persalinan dengan episiotomi dan seksio sesarea, dan selanjutnya dilakukan pengukuran fungsi seksual.

\section{Teknik Analisis Data}

Analisis statistik deskriptif terhadap data demografi sampel. Ditentukan skoring dari jawaban setiap pertanyaan dari kuisioner FSFI yang telah diisi subyek dan ditentukan jenis dan derajat disfungsi masing-masing subyek. Uji normalitas Kolmogorov-Smirnov untuk menguji normalitas data. Perbedaan antara variabel kendali (umur, agama, pendidikan, pekerjaan, tanggungan asuransi, usia kehamilan, berat badan bayi lahir, perawatan medis kembali, menyusui, bantuan pengasuh bayi, dan masalah dalam keluarga) pada persalinan pervaginam dengan episiotomi mediolateral dan seksio sesar ,diuji menggunakan analisis chisquare. Perbedaan skor FSFI antara kelompok yang melahirkan pervaginam dengan episiotomi dan kelompok seksio sesarea untuk menguji perbedaan fungsi seksual digunakan uji $t$ test jika data berdistribusi normal. Jika data tidak berdistribusi normal digunakan uji Mann-Whitney. Analisis statistik menggunakan interval kepercayaan (IK) 95\%. Hubungan dikatakan signifikan bila nilai $p<0,05$.

\section{HASIL PENELITIAN}

Telah dilakukan penelitian
mulai bulan Juli 2014 sampai 
dengan bulan September 2014, yaitu tiga bulan pasca persalinan untuk sampel yang melahirkan dari bulan April 2014 sampai dengan bulan Juni 2014. Sebanyak 90 pasien yang melahirkan di Rumah Sakit dr. Saiful Anwar Malang, terdiri dari 45 pasca persalinan dengan episiotomi mediolateral dan 45 pasca persalinan dengan seksio sesarea dilibatkan dalam penelitian ini.

\section{;Karakteristik Responden}

uji chi-square untuk variabel kendali yaitu umur, agama, pendidikan, pekerjaan, asuransi, usia kehamilan, berat badan bayi saat lahir, kondisi luka jahitan, kejadian perawatan medis/ opname ulang yang berkaitan dengan persalinannya, menyusui bayi, adanya bantuan pengasuh bayi, masalah dalam keluarga, dan saat pertama kali memulai hubungan seksual

Analisis kemaknaan dengan uji chi-square menunjukkan bahwa karakteristik subyek antar kelompok menunjukkan perbedaan yang tidak bermakna dengan nilai $p>0,05$. Hal ini berarti bahwa karakteristik subyek kedua kelompok adalah sama, sehingga pengaruhnya terhadap hasil penelitian dapat diabaikan.

Analisis kemaknaan saat mulainya hubungan seksual pasca persalinan pada kedua kelompok tidak menunjukkan perbedaan $(p>0,05)$. Pada penelitian ini saat mulai pertama hubungan seksual pada kedua kelompok adalah dua bulan pasca persalinan. Sebagian besar subyek memulai hubungan seksual pada tiga bulan pasca persalinan, baik pada kelompok pasca persalinan dengan episiotomymediolateral $(66,7 \%)$ ataupun pasca seksiosesarea $(55,6 \%)$.

\section{Fungsi Seksual pada Kelompok Pasca Persalinan dengan Episiotomi Mediolateral dan Pasca SeksioSesarea}

Fungsi seksual pada kedua kelompok episiotomi mediolateral dan seksiosesarea dilakukan uji beda dengan uji t-independent.

Terdapat perbedaan yang signifikan antara kelompok pasca persalinan dengan episiotomi mediolateral dan seksiosesarea pada variabel hasrat seksual, orgasme, nyeri, dan skor total FSFI dengan nilai $p<0.05$. Pada tabel 5.3 disebutkan bahwa rata-rata nilai total skor FSFI pada kedua kelompok masih normal (lebih dari $26,55)$, sehingga pada analisis kemaknaan disfungsi seksual antara kedua kelompok tersebut tidak berbeda signifikan dengan $p=0,081$ dimana $p>0.05$.

\begin{tabular}{crrr}
\hline Variabel & $\begin{array}{c}\text { Pasca } \\
\text { Episiotomi } \\
\text { Mediolateral } \\
(\mathbf{n = 4 5 )}\end{array}$ & $\begin{array}{c}\text { Pasca Seksio } \\
\text { Sesarea } \\
(\mathbf{n = 4 5 )}\end{array}$ & $\mathbf{P}$ \\
\hline Umur $:<17$ tahun & $3(6.7 \%)$ & $1(2.2 \%)$ & 0.435 \\
$17-35$ tahun & $40(88.9 \%)$ & $40(88.9 \%)$ & \\
$>35$ tahun & $2(4.4 \%)$ & $4(8.9 \%)$
\end{tabular}




\begin{tabular}{|c|c|c|c|}
\hline Agama : Islam & $45(100 \%)$ & 43 (95.6\%) & \multirow[t]{6}{*}{0.360} \\
\hline Kristen & $0(0 \%)$ & $1(2.2 \%)$ & \\
\hline Katholik & $0(0 \%)$ & $1(2.2 \%)$ & \\
\hline Hindu & $0(0 \%)$ & $0(0 \%)$ & \\
\hline Budha & $0(0 \%)$ & $0(0 \%)$ & \\
\hline Kepercayaan & $0(0 \%)$ & $0(0 \%)$ & \\
\hline Pendidikan : Tidak sekolah & $0(0 \%)$ & $0(0 \%)$ & \multirow[t]{7}{*}{0.617} \\
\hline SD & $6(13.3 \%)$ & $8(17.8 \%)$ & \\
\hline SMP & $9(20.0 \%)$ & $11(24.4 \%)$ & \\
\hline SMA & $20(44.4 \%)$ & $21(46.7 \%)$ & \\
\hline D3 & $1(2.2 \%)$ & $0(0 \%)$ & \\
\hline $\mathrm{S} 1$ & $9(20.0 \%)$ & $5(11.1 \%)$ & \\
\hline S2 & $0(0 \%)$ & $0(0 \%)$ & \\
\hline Pekerjaan : Ibu rumah tangga & $36(80.0 \%)$ & $37(82.2 \%)$ & \multirow[t]{5}{*}{0.798} \\
\hline Karyawan & $5(11.1 \%)$ & $5(11.1 \%)$ & \\
\hline Wirausaha & $1(2.2 \%)$ & $0(0 \%)$ & \\
\hline PNS & $3(6.7 \%)$ & $3(6.7 \%)$ & \\
\hline Pensiunan & $0(0 \%)$ & $0(0 \%)$ & \\
\hline \multirow{2}{*}{$\begin{array}{ll}\text { Tanggungan asuransi } & : \text { Ya } \\
\text { (BPJS) } & \text { Tidak }\end{array}$} & $45(100 \%)$ & $45(100 \%)$ & \multirow[t]{2}{*}{-} \\
\hline & $0(0 \%)$ & $0(0 \%)$ & \\
\hline Usia kehamilan $\quad:<37$ minggu & $2(4.4 \%)$ & $2(4.4 \%)$ & \multirow[t]{3}{*}{0.797} \\
\hline $37-42$ minggu & $39(86.7 \%)$ & $37(82.2 \%)$ & \\
\hline$>42$ minggu & $4(8.9 \%)$ & $6(13.3 \%)$ & \\
\hline Berat badan bayi lahir : $<2500 \mathrm{gr}$ & $4(8.9 \%)$ & $9(20.0 \%)$ & \multirow[t]{3}{*}{0.134} \\
\hline $2500-4000 \mathrm{gr}$ & $41(91.1 \%)$ & $36(80.0 \%)$ & \\
\hline$>4000 \mathrm{gr}$ & $0(0 \%)$ & $0(0 \%)$ & \\
\hline \multirow[t]{3}{*}{ Luka jahitan (Sembuh) } & $45(100 \%)$ & $45(100 \%)$ & \multirow[t]{2}{*}{-} \\
\hline & $0(0 \%)$ & $0(0 \%)$ & \\
\hline & $0(0 \%)$ & $0(0 \%)$ & \multirow[t]{2}{*}{-} \\
\hline (MRS Ulang) & $45(100 \%)$ & $45(100 \%)$ & \\
\hline \multirow[t]{2}{*}{ Menyusui } & $41(91.1 \%)$ & $36(80.0 \%)$ & \multirow[t]{2}{*}{0.134} \\
\hline & $4(8.9 \%)$ & $9(20.0 \%)$ & \\
\hline \multirow[t]{2}{*}{ Bantuan pengasuh bayi } & $8(17.8 \%)$ & $8(17.8 \%)$ & \multirow[t]{2}{*}{1.000} \\
\hline & $37(82.2 \%)$ & $37(82.2 \%)$ & \\
\hline \multirow[t]{2}{*}{ Masalah dalam keluarga $:$ Ya } & $0(0 \%)$ & $0(0 \%)$ & \multirow[t]{2}{*}{-} \\
\hline & $45(100 \%)$ & $45(100 \%)$ & \\
\hline
\end{tabular}

Tabel 1. Karakteristik Responden pada Kelompok Pasca Persalinan dengan Episiotomi Mediolateral dan SeksioSesarea 


\begin{tabular}{cccc}
\hline Variabel & $\begin{array}{c}\text { Pasca } \\
\text { Episiotomi } \\
\text { Mediolateral } \\
(\mathbf{n = 4 5 )}\end{array}$ & $\begin{array}{c}\text { Pasca Seksio } \\
\text { Sesarea } \\
(\mathbf{n = 4 5 )}\end{array}$ & $\mathbf{P}$ \\
\hline Saat mulai hubungan seksual : & $0(0 \%)$ & $0(0 \%)$ & 0,280 \\
1 bulan & $15(33,3 \%)$ & $20(44,4 \%)$ & \\
2 bulan & $30(66,7 \%)$ & $25(55,6 \%)$ & \\
3 bulan & $0(0 \%)$ & $0(0 \%)$ & \\
4 bulan &
\end{tabular}

Tabel 2 .Saat Mulai Hubungan Seksual pada Kelompok Pasca Persalinan dengan Episiotomi Mediolateral dan SeksioSesarea

\begin{tabular}{lccc}
\hline Variabel & $\begin{array}{c}\text { Pasca } \\
\text { Episiotomi } \\
\text { Mediolateral } \\
(\mathbf{n = 4 5})\end{array}$ & $\begin{array}{c}\text { Pasca Seksio } \\
\text { Sesarea } \\
(\mathbf{n = 4 5 )}\end{array}$ & P \\
\hline Hasrat Seksual & $3.86 \pm 1.00$ & $4.23 \pm 0.67$ & 0.045 \\
Rangsangan & $4.04 \pm 1.12$ & $4.25 \pm 0.67$ & 0.280 \\
Lubrikasi & $4.53 \pm 0.91$ & $4.77 \pm 0.55$ & 0.137 \\
Orgasme & $4.44 \pm 1.16$ & $4.83 \pm 0.45$ & 0.039 \\
Kepuasan & $4.26 \pm 1.25$ & $4.67 \pm 0.72$ & 0.058 \\
Nyeri & $4.19 \pm 1.28$ & $4.77 \pm 0.77$ & 0.010 \\
Skor Total FSFI & $30.34 \pm 7.36$ & $33.03 \pm 4.10$ & 0.036 \\
& & & \\
\hline & & & \\
Disfungsi seksual (Skor 526,55$)$ & $10(22.2 \%)$ & $4(8.9 \%)$ & 0.081 \\
$\quad$ Ya & $35(77.8 \%)$ & $41(91.1 \%)$ & \\
\hline
\end{tabular}

Tabel 3 .Skor FSFI (Female Sexual Function Index) pada Kelompok Pasca Persalinan dengan Episiotomi Mediolateral dan Pasca SeksioSesarea 


\section{PEMBAHASAN}

Hasil analisis pada penelitian ini menunjukkan perbedaan yang tidak bermakna $\quad(p>0,05) \quad$ pada rangsangan, lubrikasi, kepuasan dan disfungsi seksual, sedangkan hasrat seksual, orgasme, nyeri dan skor total FSFI pada kedua kelompok menunjukkan perbedaan yang bermakna $(p<0,05)$. Hasil penelitian ini sesuai dengan studi yang dilakukan oleh Basson pada tahun 2005. Disebutkan bahwa perempuan primipara pasca persalinan dengan episiotomi mediolateral mengalami penurunan tingkat hasrat, lubrikasi, orgasme dan peningkatan nyeri pada tiga bulan pasca persalinan dibandingkan dengan kelompok seksiosesarea. Perbedaan ini sebagian besar disebabkan karena nyeri. Selain itu, adanya kemungkinan perempuan pasca persalinan dengan episiotomi mediolateral memiliki rasa takut karena anggapan mereka bahwa perineum mereka rusak sehingga muncul gangguan lubrikasi yang mengakibatkan ketidakpuasan dan anorgasme (Basson, 2005). Perbedaan disfungsi seksual ada penelitian ini tidak signifikan bisa kemungkinan pengisian data yang subjektif dari perempuan tanpa melibatkan suami, adanya perasaan malu atau tidak jujur saat pengisian FSFI dan penelitian hanya dilakukan sekali saja saat tiga bulan pasca persalinan. Hasrat seksual pasca persalinan antara kelompok pasca episiotomi dengan pasca seksiosesarea dalam penelitian ini secara statistik menunjukkan perbedaan yang bermakna, dimana $p=0,045$. Hal ini sesuai dengan studi cross-sectional oleh Barrett, et al., (2000), yang menyatakan bahwa hilangnya hasrat seksual pasca persalinan sebesar $53 \%$ pada tiga bulan dan $37 \%$ pada enam bulan setelah melahirkan, dibandingkan dengan $9 \%$ pada kehamilan sebelumnya. Dalam studi di Nigeria, hilangnya hasrat seksual wanita pasca persalinan terjadi pada $61 \%$ dan 26\% masing-masing pada enam minggu dan enam bulan pasca persalinan (Oboro, 2002). Penurunan hasrat seksual kemungkinan disebabkan karena trauma persalinan pervaginam. Rasa nyeri dan proses persalinan yang panjang merupakan salah satu pengalaman buruk yang seringkali masih mempengaruhi hasrat seksual ketika akan memulai berhubungan. Terlepas dari berkurangnya vasodilatasi vagina secara fisiologis, faktor risiko yang berkaitan dengan penurunan hasrat seksual pasca persalinan juga dipengaruhi oleh pengalaman buruk sebelumnya (seperti akibat dari dispareunia), gangguan elastisitas vagina, kecemasan seksual, kelelahan, serta depresi. Disamping itu orientasi seksual wanita pasca melahirkan juga cenderung berubah ketika skala prioritas rumah tangga kemudian lebih mengutamakan pada pengasuhan bayi, masalah menyusui, ataupun kontrasepsi.

Pada penelitian yang dilakukan Olson dan rekan pada tahun 2005 menyebutkan bahwa penurunan atau hilangnya hasrat seksual pada periode pasca persalinan berkaitan dengan kurangnya waktu, kelelahan dari tugas-tugas yang berhubungan dengan bayi serta adanya laserasi vagina dan karena menyusui. Mereka banyak beranggapan bahwa payudara tidak lagi hanya memiliki konotasi seksual namun 
juga berkaitan dengan menyusui bayi (Leal,etal., 2013).

Rangsangan, merupakan hasil respons sensoris terhadap stimulasi seksual dimana selanjutnya menimbulkan kesiapan organ-organ seksual untuk melakukan hubungan seksual. Tidak terdapat perbedaan yang bermakna secara statistik $(\mathrm{p}=0,280)$, dalam hal rangsangan pada kedua kelompok pasca episiotomi mediolateral dan pasca seksiosesarea. Meskipun hasrat seksual menjadi menurun pasca persalinan, tetapi ketika seorang wanita mampu memusatkan diri pada stimulasi seksual yang timbul dari dalam dirinya akibat inisiatif sendiri atau akibat rangsangan seksual pasangannya, maka bukannya tidak mungkin dia dapat melewati fase rangsangan dengan baik. Jenis stimulasi, waktu yang dibutuhkan bersifat sangat subyektif dan berbeda pada setiap wanita (Windhu, 2009). Menurut Basson, dalam teori "sexual response circle", fase perangsangan (arousal) pada wanita tidak selalu didahului oleh hasrat (desire). Hasrat atau keinginan dalam berhubungan seksual timbul setelah wanita tersebut mendapatkan atau terangsang secara seksual.

Pada lubrikasi vagina disebutkan sangat dipengaruhi oleh proses menyusui. Menyusui dikatakan merupakan penyebab kekeringan vagina, dispareunia dan penurunan libido. Hal ini berkaitan dengan reaksi fisiologis hiperprolaktinemia setelah proses menyusui yang menyebabkan penurunan kadar estrogen, progesteron dan androgen. Penurunan estrogen ini memiliki dampak pada dinding vagina dan menyebabkan penurunan lubrikasi (Leal, et al., 2013).

Lubrikasi, merupakan proses sekresi mukus pada vagina yang dihasilkan oleh beberapa kelenjar vestibulardiantaranya kelenjar bartholin yang terdapat diantara himen dan labiaminora. Lubrikasi terjadi pada saat wanita terstimulasi secara seksual baik stimulasi yang dilakukan secara fisik maupun stimulasi psikis. Dalam penelitian ini tidak terdapat perbedaan yang bermakna secara statistik $(p=0,137)$, dalam hal lubrikasi pada kedua kelompok pasca episiotomi dan pasca seksiosesarea. Hal ini kemungkinan oleh karena tidak adanya gangguan dalam hal rangsangan, sehingga gairah seksual yang ditandai oleh rasa hangat atau geli pada kelamin, pelumasan (basah), dan kontraksi otot dapat terjadi secara normal. Pada episiotomi mediolateralis sayatan sengaja dilakukan menjauhi otot sfingter ani untuk mencegah rupturperinei derajat tiga ataupun empat. Bila episiotomi dilakukan dengan benar, dan tidak ada perluasan derajat ruptur, serta tidak ada gangguan dalam penyembuhannya, maka episiotomi tidak akan mengganggu fungsi kelenjar bartholin pada saat terjadinya reaksi seksual, sehingga proses lubrikasi dapat terjadi dengan baik.

Pencapaian orgasme dalam hubungan seksual antara kedua kelompok dalam penelitian ini secara statistik menunjukkan perbedaan yang bermakna, dimana $p=0,039$. Pada wanita primipara dengan seksiosesarea memiliki otot dasar panggul yang lebih kuat pada tiga bulan setelah melahirkan dibandingkan dengan wanita dengan ruptur spontan atau episiotomi. Kelahiran pervaginam paling terkait dengan relaksasi otot panggul dan episiotomi yang dilakukan tidak dapat mengurangi efek ini dan bahkan memperburuk. Dalam studi lain, Klein,et al., (2005) menunjukkan bahwa ketidakpuasan seksual perempuan lebih besar di antara wanita primipara yang melahirkan pervaginam dibandingkan dengan kelompok seksio sesarea. Kesulitan dalam mencapai orgasme dilaporkan sebesar 33\% pada tiga bulan dan $23 \%$ pada enam bulan pasca persalinan, dibandingkan dengan hanya $14 \%$ yang mengalami masalah 
ini dalam tahun terakhir sebelum kehamilan. Gangguan Orgasme juga dipengaruhi oleh adanya trauma perineum, dengan penyembuhan yang kurang baik, asimetris, sehingga nyeri yang ditimbulkan mengakibatkan ketidaknyamanan dalam hubungan seksual. Pada enam bulan pascapersalinan saat dibandingkan dengan wanita yang mengalami ruptur perineum derajat dua, tiga, ataupun empat, pada wanita dengan perineum utuh dilaporkan mempunyai fungsi seksual yang lebih baik, termasuk sensasi seksual, kepuasan seksual, dan kemungkinan orgasme. Penelitian Leal,etal., pada tahun 2013 menyebutkan bahwa kemampuan untuk mencapai orgasme diperoleh dengan cepat setelah melahirkan dalam waktu setelah enam minggu pasca persalinan.

Kepuasan seksual, merupakan kemampuan mencapai orgasme setiap kali melakukan hubungan seksual, meskipun terdapat faktor psikologis lain dalam mencapai kepuasan. Tidak terdapat perbedaan yang bermakna secara statistik, dimana $p=0,058$, pada kedua kelompok terhadap kepuasan seksual. Ketika orgasme terganggu, maka kepuasan seksual kemungkinan besar tidak akan tercapai dengan baik, meskipun terdapat faktor-faktor lain seperti kedekatan emosional yang mempengaruhi kepuasan seksual. Dalam studi lain Klein, et al., (2005) menunjukkan bahwa ketidakpuasan seksual perempuan lebih besar di antara wanita primipara yang melahirkan pervaginam dibandingkan dengan kelompok seksio sesarea.

Nyeri saat hubungan seksual dalam penelitian ini menunjukkan perbedaan yang bermakna antara kelompok pasca episiotomi dengan pasca seksio sesarea, dimana $p=0,010$. $\mathrm{Hal}$ ini sesuai dengan penelitian Baksu, et al., pada tahun 2007, dimana domain yang memiliki dampak paling besar pada nilai FSFI adalah rasa nyeri, dan kepuasan. Nyeri perineum terjadi pada $42 \%$ wanita segera setelah melahirkan, dan secara signifikan berkurang sampai $22 \%$ dan $10 \%$ pada masing-masing delapan dan 12 minggu pasca persalinan. Penelitian lain juga menunjukkan $16 \%$ tindakan episiotomi mengakibatkan lesi saraf pudenda. Lesi ini akan menjelaskan terjadinya dispareunia, yaitu nyeri genital rekuren atau persisten yang berkaitan dengan hubungan seksual pasca persalinan.

Nyeri atau dispareunia terkait dengan hubungan seksual setelah melahirkan telah banyak diteliti, walaupun temuan yang ada banyak saling bertentangan. Studi yang dilakukan Laurenco pada tahun 2014 meyebutkan bahwa wanita dengan episiotomi mempunyai intensitas dispareunia yang signifikan lebih tinggi dibanding pasca persalinan dengan seksiosesarea. Penelitian Hartman pada tahun 2005 dan Botros pada tahun 2006 menyebutkan hal yang bertentangan, yaitu persalinan dengan episiotomi tidak meningkatkan resiko dispareunia. Mereka menyebutkan bahwa tingkat nyeri antara perempuan dengan atau tanpa episiotomi selama berhubungan seksual pertama kali pasca persalinan sangat mirip. Penelitian lain yang dilakukan oleh Paterson pada tahun 2009 menyatakan bahwa nyeri yang dirasakan pada abdomen atau genital pada periode pasca persalinan terjadi hanya sekitar tiga bulan pasca persalinan (Laurenco, et al., 2014).

Secara keseluruhan dalam penelitian ini terdapat perbedaan yang bermakna secara statistik pada skor total FSFI $(p=0,036)$, akan tetapi skor FSFI masih diatas 26,55 jadi tidak tergolong disfungsi seksual. Terjadinya disfungsi seksual pada kedua kelompok tidak berbeda secara signifikan $(p=0,081)$, pasca episiotomi dan pasca seksiosesarea. Hasil ini tidak sesuai dengan penelitian Baksu, dkk. (2007), yang melaporkan terdapat 
penurunan yang signifikan dalam skor total FSFI untuk semua dimensi kunci dari fungsi seksual (hasrat, rangsangan, lubrikasi, orgasme, kepuasan, dan nyeri), antara kondisi sebelum hamil dengan enam bulan pasca episiotomi mediolateralis.

Hasil penelitian ini sesuai dengan penelitian yang dilakukan Lurie, et al., pada tahun 2013. Pada penelitian tersebut dinilai skor FSFI pada 6, 12 dan 24 minggu pasca persalinan dengan hasil tidak didapatkan perbedaan skor FSFI yang signifikan. Fungsi seksual seksual yang diukur juga tidak berbeda secara signifikan antara dua kelompok. Dalam penelitiannya Lurie, et al., menyarankan kepada perempuan yang merencanakan memilih persalinan seksio atas permintaan sendiri karena alasan timbul disfungsi seksual pasca persalinan, hendaknya lebih memilih indikasi seksio berdasarkan indikasi obstetri. Hal ini dikarenakan pada pasca persalinan dengan seksio tidaklah lebih menguntungkan dibandingkan dengan persalinan pervaginam (Lurie, et al., 2014).

Masalah emosional dan fisik pasca persalinan merupakan masalah umum dan cenderung meningkat seiring waktu. Keluhan seperti inkontinensia uri dan fekal dapat meningkat secara medis, namun masalah kesehatan emosional tampaknya tidak dikenali. Hal ini sangat mungkin bahwa ketidakharmonisan seksual merupakan penyumbang utama bagi kebahagiaan perempuan dan pasangannya. Mengingat frekuensi masalah kesehatan seksual serta morbiditas seksual pasca melahirkan, maka sewajarnyalah kita harus lebih memperhatikan penggunaan episiotomi mediolateral. Hasil penelitian kami sangat penting pada konseling wanita selama periode antenatal tentang cara persalinan dan isu-isu terkait dalam hal fungsi seksual. Kami percaya konseling seksual pasca persalinan harus menjadi bagian dari tindak lanjut antenatal, meskipun kendala yang dihadapi selama ini dalam kontrol rutin enam minggu pasca melahirkan sebagian besar wanita pasca bersalin belum memulai aktifitas seksualnya, sehingga masalah disfungsi seksual cenderung terabaikan.

\section{SIMPULAN}

Pada penelitian ini telah dilakukan penelitian Cross Sectional untuk menilai fungsi seksual antara perempuan pasca persalinan pervaginam dengan episiotomi mediolateral dan pasca seksio sesarea di Rumah Sakit dr. Saiful Anwar Malang. Tidak didapatkan perbedaan disfungsi seksual yang bermakna pada tiga bulan pasca persalinan diantara kedua kelompok. Sebagian besar perempuan memulai hubungan seksual pertama kali pada tiga bulan pasca persalinan, meskipun beberapa juga sudah memulai pada dua bulan pasca persalinan. Beberapa domain pada FSFI menunjukkan perbedaan yang signifikan diantara kedua kelompok, yaitu pada hasrat, orgasme dan nyeri, serta total skor nilai FSFI.

\section{DAFTAR PUSTAKA}

1. Abdool,Z, Thakar, R., Sultan, A.H. 2009. Postpartum Female Sexual Function: A Review. European Journal of Obstetrics \& Gynecology and Reproductive Biology; 2009.04.014

2. Baksu, B., Davas, I., Agar, E., Akyol, A., Varolan, A. 2007. The effect of mode of delivery on postpartum sexual functioning in primiparous women. Int Urogynecol J Pelvic Floor Dysfunct. 18(4):401-6.

3. Barrett G, Pendry E, Peacock J, Victor C, Thakar R, Manyonda I. Women's sexual 
health after childbirth. BJOG. 2000;107 (2) :186-95.

4. Basson, R. 2004. Revised Definitions of Women's Sexual Dysfunction. Canada : Journal of Sexual Medicine, Vol. 1, No. 1: 40-8.

5. Breslin, E.T., \& Lucas, V.A. 2003. Women's Health Nursing toward Evidence Based Practice. Missouri : Elsevier Science.

6. Buhling, KJ., Schmidt, S., Robinson, JN., Klapp, C., Siebert, G., Duden hausen, JW. 2006. Rate of dyspareunia after delivery in primiparae according to mode of delivery. Eur $\mathrm{J}$ Obstet Gynecol Reprod Biol. 124(1):42-6.

7. Klein, MC., Kaczorowski, J., Firoz, T., Hubinette, M., Jorgensen, S., Gauthier, R. 2005. A comparison of urinary and sexual outcome in women experiencing vaginal and cesarean births. $\mathrm{J}$ Obstet Gynaecol Can 27:332-339

8. Leal, Isabel., Lourenco, Silvia., Oliveira, Raquel, Carvalheira, Ana., Maroco, Joao. 2013. The Impact of Childbirth on Sexual Functioning in Women with Episiotomy. Journal of Psychology, Community \& Health. Vol. 2(3) p: 307-316.

9. Lurie, Samuel., Aizenberg, Michal., Sulema, Vicky., Boaz, Mona., Kovo, Michal. 2013. Sexual Function after Childbirth by the Mode of Delivery: a Prospective Study. Arch Gynecol Obstet Journal. Vol 10 p: 04-13

10. Oboro, VO., Tabowei, TO. 2002. Sexual function after childbirth in Nigerian women. Int $\mathrm{J}$ Gynecol Obstet. 78(3):249-50.

11. Olson, D.H, De Frain, J \& Skogrand. (2011). Marriage and families, intimacy, diversity, and strengths, Fourth Edition. Boston: McGraw-Hill
12. Windhu, S.C. 2009. Disfungsi Seksual : Tinjauan Fisiologi dan Patologis Terhadap Seksualitas. Yogyakarta : Andi. 